\title{
Analysis on the Characteristics of Particles Spectral of Ice caused by Freezing Rain in Nan-yue Mountain of Hunan Province
}

\author{
L.C. Zhang, J.L. Yang, B. Liu, K.J. Zhu \\ China Electric Power Research Institute \\ Beijing 100055, China
}

\author{
X.Y. Li \\ Institute of Atmospheric Physics \\ Chinese Academy Sciences Beijing 100029 \\ Beijing, China
}

\begin{abstract}
In order to know the formation and development micro-physical mechanism of iced-conductor in freezing rain, using the instrument of Parsivel laser droplet distribution to carry out the field observations of icing process under freezing rain in 2013 to 2014 winter in Nan-yue mountain of Hunan province.
\end{abstract}

Keywords-freezing rain; transmission line; droplet distribution; power system

\section{INTRODUCTION}

Severe icing can cause mechanical and electrical faults grid, which cause enormous economic losses. For example, the sustained bad weather (low temperature, freezing rain and snow) oc-curred in a large area of South China in 2008 caused serious influence to the safety of the grid, the direct property losses was about $10,450,000,000 \mathrm{RMB}$, and the reconstruction cost up to $39,000,000,000 \mathrm{RMB}$. In order to reduce the influence of icing on power system, many domestic and foreign scholars started research work in the field of overhead transmission line icing. Jones studied the ice thickness in different return periods with freezing rain in America and Canada, providing a basis for the design of overhead transmission line [1]. Makkonen explored the rela-tionship between ice thickness of wire and the meteorological factors, and established several numerical models for icing calculation [2-3]. In China, the study on transmission line icing mainly focused on the effects of various parameters for transmission line icing, and on ice melting for AC/DC transmission lines [4-10]. However, analyses on icing particle spectrum feature are less, mainly concentrated in Guizhou and parts of Hubei Provinces [11, 12].

In this paper, the data of particle spectrum was obtained through field observation of freezing rain and ice in Hunan Nanyue Mountain in winter of 2013-2014, and relevant parameters (freezing rain intensity, the total rainfall, radar reflectivity, number and diameter of particles) were analyzed. The results have important significance to study the Microphysical Characteristics of icing in freezing rain in the mountain area.

\section{Place AND DeVICE FOR THE OBSERVATION}

The place of field Meteorological observation was selected in NanYue mountain in the city of Hengyang, Hunan province (112.6893 degrees E, 27.2974 degrees N, respectively $1266 \mathrm{~m}$ above sea level), in the winter of 2013-2014. The type of disdrometer is OTT Parsivel2, made in Germany (shown in Figure 1). Using this device, we can observe various parameters we want, such as freezing rain drop spectrum, freezing rain intensity, the number of particles, the raindrops falling speed etc. Droplet spectrum observation data including 32 speed grades and 32 particle scale grades, the particle number for each level will be recorded and outputted every 15 seconds.

\section{ANALYSIS OF OBSERVATION RESULTS}

The freezing rain icing process occurred eight times in Nanyue Mountain in the winter of 2013 to 2014. One of the eight freezing rain processes was occurred in December 15th 2013, 08:47-18:18, which was called process A. This paper analyzed the particle spectrum characteristics in process A.

Figure 2 to Figure 5 shows the observed time series of freezing rain intensity, accumulative rainfall, radar reflectivity and particle number for process A respectively. It can be seen from FIGURE I that, the maximum freezing rain intensity of process A was about $4-4.5 \mathrm{~mm} / \mathrm{h}$, according to the three minutes of moving average curve, the main peak of freezing rain intensity was about $2.5 \mathrm{~mm} / \mathrm{h}$, it was below $2 \mathrm{~mm} / \mathrm{h}$ in most of the time section. 


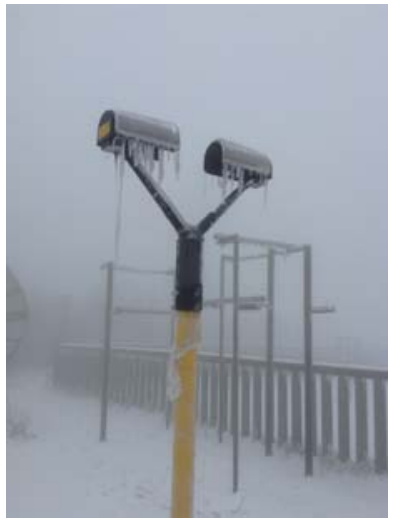

FIGURE I. PARSIVEL LASER RAINDROP SPECTRUM INSTRUMENT.

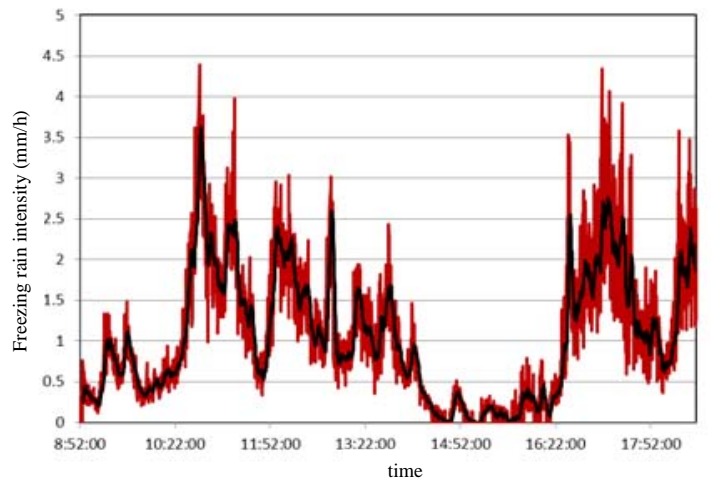

FIGURE II. TIME SERIES OF FREEZING RAIN INTENSITY (RED LINE) AND THE AVERAGE MOVING TIME SERIES (BLACK LINE) FOR PROCESS A.

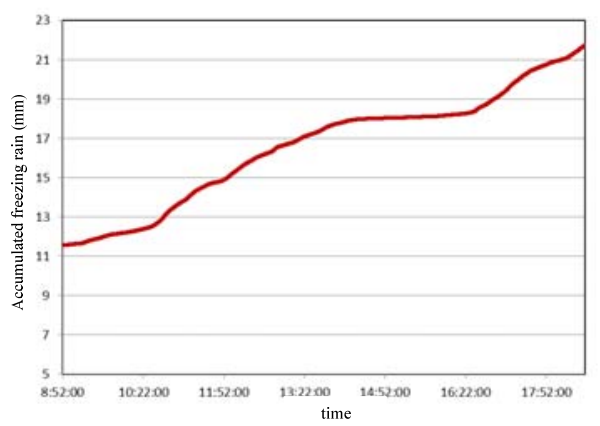

FIGURE III. ACCUMULATED RAINFALL TIME SERIES OF PROCESS A

It can be seen from Figure 3 that, the accumulated rainfall was about $10 \mathrm{~mm}$ in the time period of 08:47 to 18:18 during the freezing rain process. However, the accumulated rainfall in the time period of 08:00 to 20:00 was about $14.1 \mathrm{~mm}$ by artificial observation, which was higher than the former. It is due to the observation error between different instruments at different observation periods.

It can be seen from Figure 4 that, in the freezing process of December 15th 2013, the basic reflectivity in Nanyue Mountain changed from weak to strong. The radar echo was bellow $20 \mathrm{dBZ}$ at 09:00 AM, and it changed between 20 to $25 \mathrm{dBZ}$ at 12:00 AM.
In the afternoon, the new cloud formatted, and moved north to Nanyue Mountain area, then the maximum radar reflectivity reached 30 to $35 \mathrm{dBZ}$. In the picture of radar reflectivity calculated by raindrop spectrum, the radar reflectivity was below 20dBZ at 09:00 AM, and it changed between 20 to $25 \mathrm{dBZ}$ at 12:00 AM. At 18:00, the radar reflectivity was about 30dBZ, which was in good agreement with the result of Doppler radar observations. The main radar echo was below 30dBZ in process A, 20-25dBZ in the main precipitation period.

It can be seen from Figure 5 that, the maximum quantity of freezing rain particles in 15 seconds of the observation period achieved 450, the three minutes sliding average particle number had reached 350, the particle number distribution and the change of freezing rain intensity had the same trend. However, the precipitation particle quantity was less at 16:00, but the freezing rain intensity was still as much as the strength of 11:00, which means the freezing rain particle size having larger increase in the afternoon.

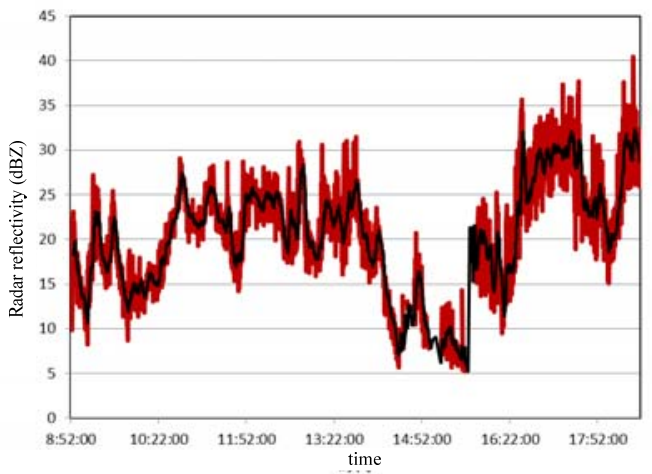

FIGURE IV. RADAR REFLECTIVITY TIME SERIES (RED DASHED LINE) AND RADAR REFLECTIVITY MOVING AVERAGE TIME SERIES (BLACK LINE) OF PROCESS A.

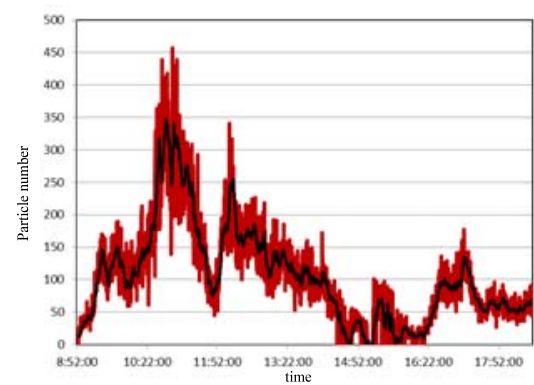

FIGURE V. PARTICLE NUMBER TIME SERIES (RED DASHED LINE) AND PARTICLE NUMBER MOVING AVERAGE TIME SERIES (BLACK LINE) OF PROCESS A.

In the different freezing processes, the relationship between diameter of freezing rain drop spectrum and the particle number was closer. It can be seen from Figure 6 that, during process A, the corresponding particle diameters were $0.5 \mathrm{~mm}$ and $0.625 \mathrm{~mm}$ in the high value area of particles number (more than 60000). The other freezing rain processes had a similar phenomenon. Therefore, in the high altitude mountain, freezing rain is composed of rain and drizzle, and the particle number of rain was more than that of drizzle. 


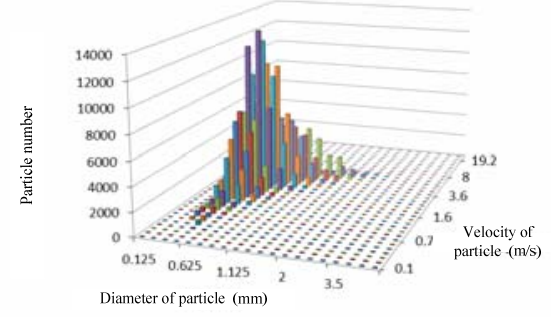

FIGURE VI. (A) DROPLET SPECTRUM DIAMETER, VELOCITY AND PARTICLE NUMBER DISTRIBUTION MAP OF PROCESS A.

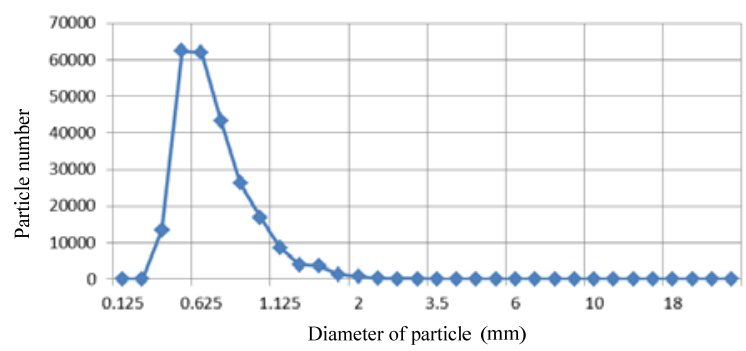

FIGURE VI. (B)RELATIONSHIP BETWEEN DROPLET SPECTRA DIAMETER AND PARTICLE NUMBER.

\section{SUMMARY}

(1) The maximum range of radar reflectivity for freezing rain was 30 to $35 \mathrm{dBZ}$, the radar echo in most of the freezing rain process was bellow $25 \mathrm{dBZ}$, and the radar reflectivity calculated by spec-trometer was good agree with the radar observations.

(2) During freezing rain processes, the raindrop diameters were mainly concentrated in the drizzle level $(<0.5 \mathrm{~mm})$ or above, most of them were about $0.625 \mathrm{~mm}$. The number of particles (whose diameter were larger than $0.5 \mathrm{~mm}$ ) is more than the number of drizzle particles. In the ic-ing process of high altitude mountain, the contribution for ice growth making by cooled raindrops (whose diameter is greater than or equal to $0.625 \mathrm{~mm}$ ) is greater than that of the drizzle $(<0.5 \mathrm{~mm})$.

\section{REFERENCES}

[1] Jones, K. F, Neal L. Ronald T. Extreme ice from freezing rain. New Hampshire: American Lifelines Alliance, 2004.

[2] Sundin E, Makkonen L. Ice loads on a lattice tower estimated by weather station data. Journal of applied meteorology, 1998, 37(5): 523-529.

[3] Makkonen l, Kari A. Climatic mapping of ice loads based on airport weather observatioins. Atmospheric Research, 1995, 36(3-4): 185-193

[4] Xingliang Jiang, Jun Ma, Shaohua Wang, et al. Transmission lines' ice accidents and analysis of the formative factors. Electric Power, 2005,38(11): 27-30.

[5] JiahaoXu, Wei Zhang, Xiaoning Huang, et al. Transmission line icing prediction model under micro-meterological conditions. Electric Power, 2014, 47(2): 58-63.

[5] Jiazheng Lu, Hongxian Zhang, JiwenPeng, et al. Calculation of Hunan power grid icing recurrence interval based on extreme-value type I probability distribution model. High Voltage Engineering, 2012, 38(2): 464-468.

[6] GuoyiNie. Discussion about the icing load on conductors of overhead transmission lines. Electric power construction, 1992, 13(7): 46-54.
[7] Guanri Tan, Bing Wang, Jian Qin, et al. Calculation of the extreme ice thickness for conductors. Electric Technique, 1983(2):8-14.

[8] Jiazhen Lu, Hongxian Zhang, JiwenPeng, et al. Calculation of Hunan power grid icing recurrence interval based on Pearson III type probability distribution. Transactions of China electrotechnical society, 2013, 28(1):80-86.

[9] ZhichongGuo, Jiazheng Lu, Zhangqing Yu, et al. Analysis on induced voltage of deicer for UHV double-circuit transmission line on the same tower. Power system technology, 2013,37(11):3015-3021.

[10] Ran Jia, ShengjieNiu, Rui Li. Observational study on microphysical characteristics of wire icing in west Hubei, ScientiaMeteorologicaSnica, 2012, 30(4): 481-486.

[11] ShengjieNiu, Yue Zhou, Ran Jia, et al. Preliminary study of the microphysics of ice accretion on wires: Observations and simulations. Science China Earth Science, 2011, 41(12): 1812-1821. 